\title{
Power-ing up neo-aristotelian natural goodness
}

\author{
Ben Page $^{1}$ (D)
}

Accepted: 22 February 2021 / Published online: 16 March 2021

(C) The Author(s) 2021

\begin{abstract}
Something is good insofar as it achieves its end, so says a neo-Aristotelian view of goodness. Powers/dispositions are paradigm cases of entities that have an end, so say many metaphysicians. A question therefore arises, namely, can one account for neo-Aristotelian goodness in terms of an ontology of powers? This is what I shall begin to explore in this paper. I will first provide a brief explication of both neo-Aristotelian goodness and the metaphysics of powers, before turning to investigate whether one can give an account of neo-Aristotelian goodness in terms of powers. I will suggest that the answer to this question is yes.
\end{abstract}

Keywords Goodness · Powers · Neo-Aristotelian · Teleology

\section{Power-ing up neo-aristotelian natural goodness ${ }^{1}$}

Something is good insofar as it achieves its end, so says a neo-Aristotelian view of goodness. Powers/dispositions are paradigm cases of entities that have an end, so say many metaphysicians. ${ }^{2}$ A question therefore arises, namely, can one account for neo-Aristotelian goodness in terms of an ontology of powers? This is what I shall

\footnotetext{
1 Previous versions of this paper were presented at the 2019 HEAT conference in Helsinki and to an audience at the University of Notre Dame. I would like to thank the audience members at both for all their valuable feedback. I also wish to acknowledge Anna Marmodoro, Matthew Tugby, Tim Pawl, Christopher Shields and the anonymous reviewers at Philosophical Studies for their insightful comments on earlier drafts.

${ }^{2}$ I use the terminology of powers and dispositions interchangeably.
}

Ben Page

ben.page@philosophy.ox.ac.uk

1 Pembroke College and Oriel College, University of Oxford, Oxford, UK 
begin to explore in this paper. I say begin because it will become apparent that there are many issues which I admit require further investigation beyond what I can say here. Perhaps this isn't particularly surprising, since when one tries to answer a big question by bringing together topics from different domains of philosophy that have had very little interaction with one another, there ends up being too many details to be fully addressed in one paper alone. Nonetheless, I hope to provide a general blueprint for how an account might go, with future work focusing on specific areas of this blueprint in more detail. With that said, the structure of the paper will be as follows. I will first provide a brief explication of both neoAristotelian goodness and the metaphysics of powers, ${ }^{3}$ and then turn to investigate whether one can give an account of neo-Aristotelian goodness in terms of powers. I will suggest that the answer to this question is yes.

\section{Neo-aristotelian goodness}

Oderberg writes, the good is 'that which satisfies a thing's natural appetites, or that which fulfils a thing's nature.' (2000, 37; 2020, 14) I take this definition to contain the key components of what is called neo-Aristotelian goodness (Hursthouse, 2013). ${ }^{4}$ It is important to note that this type of goodness thinks 'there is no such thing as being just good or bad, there is only being a good or bad so-and-so.' (Geach, 1956, 33) As such, 'In 'a good F', the concept ' $F$ ' will involve some sort of goal, or function, or role, or characteristic mode; hence being a good doctor, or a good parent, or a good neighbour, is a matter of doing what can reasonably be expected of a person with that goal, or function, or role, or characteristic mode.' (Teichmann, 2011, 89) Given this, what is good for $X$ may not be good for $Y$. Thus, in terms of Oderberg's definition above, natures have ends, or can be fulfilled, and the good is fulfilling these natures. What exactly these natures are varies somewhat between theorists, with some making use of 'Aristotelian categoricals' (Thompson, 1995, 2008; Foot, 2001, 27-34; Lott, 2012), ${ }^{5}$ whilst others opt for some type of object essentialism (Feser, 2014b; Oderberg, 2010). ${ }^{6}$ Nevertheless, what is vital to both is that natures have functions or ends, where these notions of function or end

\footnotetext{
3 Note that I will be arguing for neither and assuming a non-reductive view of powers.

${ }^{4}$ Neo-Aristotelian goodness is typically taken to be a naturalist meta-ethic, although this has been questioned (Hursthouse, 2013, 3571).

5 The language of life form may be used instead, but note that a life form is constituted by a set of Aristotelian categoricals which specify what characteristically happens in the lifecycle of a member of a given species. (Crane \& Sandler, 2011, 299).

6 It may be that 'Aristotelian categoricals' also require object essentialism, since the statements these express have been called 'essence-expressing generics' (Frey, 2019, 96). Further, note that the type of essentialism typically employed here is not modal essentialism, but rather a definitional essentialism (Fine, 1994; Lowe, 2018; Oderberg, 2007).
} 
are not statistical concepts, but rather inherently naturally normative. ${ }^{7}$ In other words, even if most people became blind, that would not mean that the nature, function or end of an eye was no longer to see. Rather the eye's function to see remains regardless of the statistics of seeing eyes. Further, this normativity is also thought to enable us to make value judgements, such that non-seeing eyes are defective or bad, whilst seeing eyes are good. ${ }^{8}$

We might be inclined to ask a further question, namely, what accounts for this normativity of natures, functions or ends on this account? I suggest the answer neoAristotelians about goodness will give is that these things are normative in virtue of them being teleological. ${ }^{9}$ This is taken by many to be the view of Aristotle, (see e.g. Loux, 2014, 162, n.30; Witt, 2008, 105; Makin, 2006, 194-196), and has also been embraced by a number of philosophers more generally. For instance, Bauer writes, 'To ascribe a telos is to ascribe a norm or standard of performance' $(2009,239)$, Koons asserts that 'Normativity is generated by teleology' $(2000,167 ; 2017,6)$ and Okrent claims that 'teleological explanations are, intrinsically, normative.' (2018, 43). For the purpose of this paper I shall take this to be correct, given my assumption of a neo-Aristotelian account of goodness. ${ }^{10}$

The bare bones version of neo-Aristotelian goodness therefore requires something fulfilling or reaching a teleological end where this end is determined by the type of entity in question. This latter qualification is important, since we do not want to say that the fulfilling of any end is good, but rather only the ends that are proper to the entity in question. Put more concretely we can say that a plant seed has a nature inherent to it, such that this nature determines its teleological ends. The plant is a good plant insofar as it reaches these ends and bad insofar as it doesn't. We can also make further distinctions regarding goodness on this account. The type of good I have just spoken about we will call the "attributive account of good", whilst we will call something being good for some entity $X$ the "relational account of good". Finally, we have another type of goodness which claims that something is good in virtue of $X$, what I'll call "derivative goodness". ${ }^{11}$ In terms of the plant example above, something is relationally good for the plant when it helps it become

\footnotetext{
7 There are many different types of norms (Okrent, 2018, 2-3), and within contemporary philosophy talk of normativity typically concerns the normativity of agents. Neo-Aristotelians about goodness think nature is normative as well, which is why I use the phrase 'naturally normative'. As such whenever I speak about normativity it is this I will be referring to.

${ }^{8}$ It isn't clear as to whether all norms give rise to values. For instance, take Lowe who thinks that laws of nature are normative entities (Lowe, 2009, 141-163). Whilst he sometimes uses evaluative concepts in virtue of things going against the normative laws, such as the terminology of abnormal and defect, I have spoken to others who hold to a normative view of laws but take it to be an open question as to whether these give rise to values. For the purpose of this paper, norms will provide us with values.

9 That neo-Aristotelian theories of goodness are teleological is embraced by both those employing Aristotelian categoricals (Frey, 2019, 98; Crane \& Sandler, 2011, 290, 300, 305-306; Foot, 30-33; Lott, 2012) and those who prefer the notion of essence (Feser, 2014b, 84; Oderberg, 2010).

${ }^{10}$ Working out the precise details of how teleology and normativity relate will have to wait for another time, since questions have been raised about this (Silverstein, 2016).

11 There is also another type of goodness usually talked about in the literature, the predicative account of good, which claims that something can be good simpliciter. Since many neo-Aristotelians deny the existence of this type of good, I shall have nothing more to say about it here.
} 
a good plant, such as water, soil, nutrients, sunlight, etc. and bad for the plant when it hinders this. Whilst, something is derivatively good for the plant if it is a feature of the plant which helps it fulfil its flourishing. For example, the leaves of the plant are derivatively good since they allow for photosynthesis to take place which benefits the whole plant. As the attributive account is key to both the relational and derivative accounts of goodness, due to it determining their content, it is the one that I shall be primarily concerned with in this paper. As such I will say that something is attributively good, when it fulfils or reaches its teleological end where this end is determined by the entity in question. ${ }^{12}$

Before turning to the metaphysics of powers, let me state that the type of goodness I shall be concerned with in this essay is natural goodness (Foot, 2001), where this contrasts artefactual and moral goodness. This is not to claim that artefactual and moral goodness are wholly different and not related to natural goodness, but rather that I cannot get into these complexities in a single paper. As such I won't address these topics any further, since this is an already ambitious paper and restricting the account to natural goodness is plenty to be dealing with already! ${ }^{13}$

\section{Powers}

There seems to be a feature of powers that has been overlooked which enables them to be used in our theory of goodness, namely that they have an end, or their directedness. Before commenting on this let me provide a brief recap as to what neo-Aristotelian powers are. ${ }^{14}$

We can ascertain some features of powers through looking at examples. Salt has the power to dissolve in water, my eyes have the power to see, and an entity with negative charge has the power to repel other negatively charged entities. First, powers are thought of as being a type of property. Second, powers are typically defined by the change they bring about and the conditions in which this change will be brought about, that is, their manifestations and conditions for manifestation. Third, manifestations are only thought to occur when a power is in certain circumstances. Fourth, powers exist even when they aren't manifesting. For instance, salt has the power to dissolve even if that power never manifests. Fifth, powers are taken to be non-reductive in that their causal nature or modality cannot be reduced to something else, such as categorical properties. Finally, powers are directional entities, that is they have an end. It is this feature of powers that I think will help explain how powers can provide an account of neo-Aristotelian goodness, and so I further explicate this now.

\footnotetext{
${ }^{12}$ Note that this means there will likely be levels of goodness, in that an end may be more or less closely reached.

13 Given this, when I speak of goodness I will mean natural goodness, unless otherwise stated.

14 For more, see my introduction to the metaphysics of powers (Page, forthcoming).
} 
Directedness is 'in some sense' a feature of powers that any theory must account for (Place, 1999, 227). Yet how power theorists explain directionality varies. For instance, one prominent theory thinks of directionality as a type of 'physical' or 'natural intentionality' ${ }^{15}$ However, I intend to rely on a different explanation of the directionality of powers, namely that powers are teleological. ${ }^{16}$ It is important to note from the outset that powers being teleological does not imply that they have conscious awareness. ${ }^{17}$ All that's required is that there is an end state or goal of a power. Let me also make a distinction between two types of teleology: external and internal. External teleology is extrinsically imposed on some entity whilst internal teleology is intrinsic to an entity. For instance, the pieces of my watch are placed together in such a way that my watch has the power to tell the time. This end of my watch is a type of external teleology, since the pieces of my watch wouldn't tell the time on their own, rather they must be ordered and arranged externally so that they do. Contrast this with the teleology we find in an acorn. Here the acorn is teleologically directed to become an oak tree, where this teleological feature is implanted into the very nature of the acorn, not something externally imposed on it. For the purpose of this paper when I speak of teleology, unless otherwise stated, I will have in mind internal teleology. ${ }^{18}$

That a significant number of power metaphysicians hold that powers are teleological might come as surprise to many philosophers outside this discussion, with Koons, for instance, writing 'causal powers are inherently teleological.' (2017, 15-16) Many other examples of those who say similar things could be given. ${ }^{19}$ Further it may also be the case that those who try to explain a power's directedness in terms of function (Mumford, 1998; Whittle, 2008) or intentionality may also be reliant on a teleological account. This is because functions, and intentionality may both be explained by teleology. ${ }^{20}$ Whether this is the case or not I leave it to my

\footnotetext{
15 Molnar (2003, 60-81) uses 'physical intentionality', Heil (2003, 221), 'natural intentionality', and Martin (2007, 178), Place (1999, 227), and Borghini (2009) use intentionality. This view has been challenged by a number of theorists (Bird, 2007, 114-126; Oderberg, 2017), with some of these difficulties receiving replies (Bauer, 2016).

16 Some employ the language of finality instead of teleology.

17 This was also true of Aristotelian teleology, see Ariew (2002).

18 Artefacts are typically thought of as paradigm exhibitors of external teleology. This difference is one reason that I do not speak about artefactual goodness within this paper. There is also another distinction that concerns teleology, namely, powers that have a definite end state, and those which do not, where this, according to Beere, corresponds to Aristotle's use of entelecheia and energeia, fulfilment and activity respectively $(2009,162)$. For our purposes either of these is a way that powers could be teleological and as such both types of powers can/could play a role in the theory of goodness I give.

19 For instance, see: Austin (2019, 41), Lisska (1996, 99; 2016 121); Kroll (2017), Oderberg (2017), Witt (2008, 130), Feser (2014a, ch.2; 2014b, 93), Austin and Marmodoro (2017), Koons and Pruss (2017), and Schmid (2011). (Note that those who use the term disposition in the references above use the term synonymously with what I mean by power). McKitrick might also advocate teleology, but it's unclear. She writes, 'Insofar as dispositions are directed at their manifestations, a teleological directedness seems like a plausible way to go.' $(2017,42)$.

${ }^{20}$ For instance, see Haldane (1999, 41), Lisska (2016, 70), Okrent (2007), Bauer (2009, 239) and Koons (1998, 559).
} 
reader to decide, but for the purpose of this paper I will think of powers as teleological. $^{21}$

The reason why this matters, is that given that powers are teleological we can also think of them as possessing natural normativity and hence being evaluative. ${ }^{22}$ This view might cause a concern that there is normativity all the way down in nature, to the very fundamental level. But why be concerned about this? Natural normativity has failed multiple attempted reductions, so perhaps we do indeed have normativity all-the-way down (Bohn, 2018). In any case, neo-Aristotelians typically think nature is inherently normative, and insofar as I am assuming their view of goodness I'm unconcerned by this objection. ${ }^{23}$

With this aspect of powers explicated, I'm now able to start providing a metaphysical account of neo-Aristotelian goodness. ${ }^{24}$ The general idea will be that goodness is thought of in terms of fulfilment, and the fulfilment, in my case, will be the fulfilment of powers reaching their teleological end, their manifestation. ${ }^{25}$ Exploring some of the details and potential problems of such an account is what I now turn to.

\section{Power-ing up neo-aristotelian natural goodness}

A powers theory of neo-Aristotelian natural goodness holds that goodness is a power fulfilling or reaching its teleological end, with this end being determined by the nature of the power and also providing its natural norms. As I have already

\footnotetext{
${ }^{21}$ An objection Manley and Wasserman $(2017,48)$ offer against thinking about powers as teleological is that directedness is less mysterious than teleology. I suggest a reply to this would claim that directedness just is a teleological notion, and indeed a number of people have said something like this in other contexts (Oderberg, 2020, 28; Feser, 2014a, 88-105).

${ }^{22}$ Some power theorists are explicit that powers give rise to normativity (Koons, 2017, 15; Koons \& Pruss, 2017, 198-199; Schmid, 2011, 36; Witt, 2008). Kroll (2017) may also think this insofar as he quotes Makin (2006) and seems to agree with him on this. However, let me note that if one didn't think that teleology provides normativity, what I say will be compatible with a view where powers are normative entities, a view Mymford and Anum $(2011,184)$ attribute to Lowe $(1989$, ch.8).

${ }^{23}$ Another question might be whether one could provide a reductive account of teleology? There have been numerous attempts to do so, however I suggest all accounts fail and we should think of this teleology non-reductively (Rea, 2002, 108-127; Plantinga, 1993, 194-211; Koons \& Pruss, 2017, 199-203). An alternative would be to claim that there are differing accounts of teleology, each performing different roles. We could then adopt a pluralist theory so to claim that the differing conceptions of teleology or function, while valid, do not compete (Hacker-Wright, 2013, 123-124). Crane and Sandler (2011) provide an example of this when thinking about the normative concept of species which is typically employed in neo-Aristotelian accounts of goodness, but one could adopt a parallel approach for teleology.

${ }^{24}$ This account will take some inspiration from Lisska's (1996) interpretation of Aquinas's theory of goodness.

${ }^{25}$ I should note that there are some who think that powers are teleological, but do not think that this teleology extends to providing an account of the good (Kroll, 2017, 22-23; Austin, 2019, 137). This contrasts with many, such as Kenny, who writes, 'Any teleological explanation must involve an activity which can be done well or badly, or an entity for which there can be good or bad. ... There are two ways in which things may have purpose: they may exist to serve a purpose, and they may act for a purpose.' (1988, 78).
} 
noted, the end to which powers are directed is their manifestation, with the specifics of that manifestation depending upon the nature of the power in question. I also add the condition that a 'good' power is one that reaches its end if it is in the appropriate conditions to do so. ${ }^{26}$ As such a power which manifests but does so in the wrong conditions is not a good power. Similarly, a power that manifests in the right conditions but with the wrong manifestation is not a good power, since it too deviates from its natural norm. For a power to be good, both conditions must be met, namely right manifestation in the right conditions.

A question arises; what are we to say about powers which do not manifest, but don't do so because they are not in the right conditions? These powers do what they are supposed to given their nature, which is not to manifest. As such, should we take them to be fulfilling their nature and thereby good $?^{27}$ There seem to be two options before us in answering this question. The first is to claim that insofar as powers are obeying their natures they are good. Hence a power that does not reach its end because it's in a situation where it should not is acting in accordance with its teleological nature and is therefore good. The second claims that the power in question is neither good nor bad in virtue of it not manifesting when it should not, but rather axiologically neutral or indifferent. ${ }^{28}$

Note also that on some metaphysical conceptions of powers we may not have to answer this question. For instance on views where powers are initially dormant and only manifest, or try to achieve their end when the right conditions come along (McKitrick, 2018, ch.6), we will need an answer to this question. By contrast on views of powers where a power is never dormant but instead constantly manifesting, and trying to achieve its end, we will not. ${ }^{29}$ This is because there is no time at which powers are not manifesting in certain conditions, since they are always manifesting, with the outcome of their manifestation being dependent upon the conditions they find themselves in. Insofar as they are acting in accordance with their nature, these manifestations will be achieving their good. ${ }^{30}$

Let me also note an additional complexity to any theory of goodness based on powers, namely as to whether one adopts a view where powers are single-track or

\footnotetext{
${ }^{26}$ Note that this condition is inbuilt into most theories of powers, since if the stimulus conditions for a power's manifestation is contained within the definition of the power itself, then the power will only ever manifest in the appropriate conditions. However, Vetter $(2015$, ch.3; 2014) removes stimulus conditions from her definition of powers, and so she may require this second condition for my theory of goodness.

27 Note that this type of question is not particular to the powers account I am constructing and can be asked of standard accounts of neo-Aristotelian goodness.

28 Oderberg $(2020,24)$ seems to think something like this on his neo-Aristotelian account of goodness.

29 Dumsday (2016a) attributes this type of view to Lowe and Marmodoro (unpublished) holds something similar.

${ }^{30}$ Note that in many instances of natural things, these powers will have no choice but to obey their nature.
} 
multi-track. ${ }^{31}$ Briefly the distinction, as I intend it, says that single-track powers have only one 'type' of manifestation, and as such the power's identity is determined by a single manifestation. ${ }^{32}$ By contrast multi-track powers have multiple 'types' of manifestation, and as such their identity is not determined by one manifestation type. Whether multi-trackers can give a sufficient account of a power's identity has been a topic of debate and not one I will engage here. ${ }^{33}$ Nevertheless let me briefly note how adopting single-track and/or multi-track powers could impact a power's theory of goodness.

For single-trackers there is only one end for each power to reach and when a power reaches that end in the appropriate circumstances, it is good. ${ }^{34}$ Note also, that given the nature of single-track powers, that for every distinct type of goodness, there will need to be a distinct power, as single-track powers only have one end. By contrast, as multi-track powers have multiple ends, one multi-track power could potentially account for multiple types of goodness, with these being accounted for by different tracks of the one power. ${ }^{35}$ Yet how should we think about a multi-track power being good? Imagine for the moment a multi-track power with three different tracks/ends. Just as before we can say that a multi-track power is good insofar as it reaches its end in the right circumstances, since the different tracks of a multi-track power only manifest when their individually appropriate manifestation conditions are met. ${ }^{36}$ As such track one only manifests in certain situations, track two in others, and likewise for track three. One option then would be to say that a multi-track power is good as long as at least one track is manifested. ${ }^{37}$ This seems to be what we have to say in the case of multi-track powers which cannot simultaneously manifest more than one track. However, if there are or can be multi-track powers that simultaneously manifest multiple tracks, we may wish to say something different. For instance, perhaps we should say that a power that manifests all of its tracks at once is more good, than a power that just manifests one of them, even though this is good to a lesser extent. I suspect that whether we should say this will depend upon

\footnotetext{
31 There may be different types of multi-track powers, namely quantitative and qualitative. Roughly put, a quantitative multi-track power says an individual power has only one 'type' of manifestation, but that this one 'type' can manifest to various degrees, e.g. elastic's power to stretch to various lengths. By contrast a qualitative multi-track power holds that an individual power can have multiple 'types' of manifestation. It is this latter type of power that is more controversial and the one I shall focus on here. Nevertheless, it is worth noting that quantitative multi-track powers may help one account for degrees of goodness, although this is not something I'll comment on further here.

32 Or on many views partly determined, since the manifestation conditions are also required to determine a power's identity. See footnote 26 for a view that doesn't.

33 Two paradigm papers concerning multi-track powers are Lowe (2010), arguing against them, and Williams (2011), arguing for them.

34 This ignores what we should to say about the goodness of a power which does not manifest because it is not in the right conditions.

35 Identifying what these ends are and spelling out the identity conditions of these powers is difficult, but it is a difficulty with multi-track powers more generally rather than for this account specifically. As such I won't comment on it further here.

36 Something slightly different may have to be said on a view of powers where they constantly are manifesting and trying to achieve their ends.

37 With this also ignoring what was ignored in footnote 34 .
} 
the exact nature of multi-track powers, and exploring this further will have to wait for another occasion.

Whilst this complexity is one that deserves further attention, both in general and in regard to the view of goodness I'm constructing, what I say in the proceeding sections I hope to be largely accommodatable by both single-trackers and multitrackers. However when the distinction is particularly relevant I will draw attention to it.

\section{Powerful tropes and no objects}

I begin by thinking about an account of neo-Aristotelian goodness that is based on a world of power tropes and no composition. I do this for two reasons. First since a trope theory of powers has been defended in the literature (Marmodoro, 2017a, 110; Jaworski, 2016, 60), ${ }^{38}$ and second in order to remove objecthood from playing a role in the theory of goodness. On this view the attributive good of a power is it reaching its end, namely manifesting. We can also say that there is a relational good for the power, namely that which helps the power reach its end. However, it is more difficult to say that there is derivative goodness, since this claims that a power is good in virtue of some other feature of it, yet since I have removed the possibility of composition it is not clear what this would be. What then should we make of a theory like this?

I suspect many will think it should be rejected due to several reasons. Here is one, what I call the "problem of permissiveness", which claims that the account is too permissive in terms of what can be good. The reason for this is that all powers are directional entities, since it is part of their nature that they are teleologically directed towards their manifestation, and as such all powers would therefore seem to be involved in goodness. But do we really think this is the case? Does the manifestation of negative charge repelling other instances of negative charge mean that the power has flourished such that it is a good instance of its kind? The too permissive worry says the answer is no, and since the theory I have given claims the answer is yes then so much the worse for the theory. ${ }^{39}$ What is therefore being asked is whether we can restrict what the theory says can be good.

Before turning to whether this can be done, note that given certain conceptions of powers, the view might be thought too permissive in another respect, namely in

\footnotetext{
${ }^{38}$ Arguably I could also make do with Rea's postulation of primitive powers (2011) especially as these seem in many ways like power tropes (Jaworski, 2016, 332-333). Note that theorists would not agree with the claim that there are no objects.

39 As this objection is based on one's intuitions it will be defeasible and may not be universally held. After all, some neo-Aristotelians about goodness think some seemingly quite strange things count as goods. For instance, Oderberg speaks of instantiation as a good (2020, ch.3), whilst others think of existence as a good (Cronin, 1930, 90; Oderberg, 2020, ch.3). Given this, it might be that certain goods we initially thought of as strange and needing rejecting are in fact not so odd to neo-Aristotelians and therefore won't be rejected. Nevertheless, many, perhaps most neo-Aristotelians about natural goodness, have restricted accounts (I suspect this is also the case for Oderberg and Cronin), although the degree of their restriction varies.
} 
that it claims there are too many instances of goodness in the world. To see this remember that some power theorists hold that powers are dormant and then active, whilst another view holds that powers are never dormant but constantly manifesting, and acting to bring about their end. On the former view the instances of goodness in the world is dependent on how many powers are no longer dormant and instead achieving their end, where this could plausibly vary considerably over a period of time. ${ }^{40}$ By contrast, on the latter view, where powers are never dormant, powers are always good when they are manifesting, so long as they are manifesting as they ought to given the circumstances they are in. On this view, powers are therefore only bad if they malfunction, and if we think that power tropes of the natural world will malfunction only fairly infrequently, ${ }^{41}$ then the world will be largely full of instances of goodness, since powers will be achieving their end and hence good. This, however, would seem to go against most people's intuitions regarding how many instances of goodness there are in the world and how constant this remains across time. ${ }^{42}$ Perhaps people are just wrong in their assessment, or perhaps the wrongness lies with the theory instead.

Turning back to the original problem of permissiveness, is there a way to restrict the set of powers which can be said to be good when they manifest? Here is one option. Maybe one could claim that the living exhibit some distinctive type of teleology which distinguishes it from the non-living, ${ }^{43}$ and only powers with this type of teleology can be good when they manifest. ${ }^{44}$ What is important about this type of teleology, so say it's advocates, is that it's self-perfective. Yet it is hard to see how a power trope can perfect itself other than by merely achieving its end. But if that's the case then we haven't restricted the domain of powers at all. If we build more into the notion of self-perfection then it appears we will no longer be nihilists about mereology, since a typical example of self-perfection is metabolism (Shields,

\footnotetext{
40 This view might lead to another objection raised by Tim Pawl to me, what I call the "maximise manifestations" objection, which holds that if we assume that we should bring about as much goodness as possible and that every instance of goodness is equal in value to every other then what we should be doing is bringing about the manifestations of as many powers as possible. This does seem an odd result and undesirable. Perhaps, following a suggestion by a reviewer, one could claim that thinking of the world as being good or better, with the presumption that we should always aim at maximising the total goodness, is a very non-Aristotelian way of thinking about value and that therefore the Aristotelian should reject the basis of this objection.

41 Whether natural powers do or don't malfunction infrequently will be a matter of debate, and I suspect will largely depend on the nature of powers one adopts and how one understands what it is for them to malfunction.

42 Note that the former view of powers, in which they can be both dormant or active, would also be subject to this worry if it held that powers were good insofar as they did not manifest in the wrong circumstances. However, perhaps we could overcome this concern by adding further complexity to the theory, by saying that although a power not manifesting because it ought not to has value, it only has little value, whilst a power manifesting in the conditions it ought to has more value. As such the world might still have more instances of value than we had originally thought, but there could be more permutations as to how much value was in the world due to the additional value of manifestation.

43 Something like this has been claimed by a number of people (Oderberg, 2007, 177-200; Shields, 2012; Feser, 2019, 375-383; Rosenkrantz, 2012; Okrent, 2007, ch.2; Des Chene, 2000, 57-63).

44 Some neo-Aristotelians about natural goodness restrict goodness to living beings (e.g. Foot, 2001).
} 
$2012,177)$, and this seems to require objects rather than individual power tropes. ${ }^{45}$ As such I don't think that there will be any power tropes that will be able to satisfy a robust notion of self-perfection.

An alternative suggestion would be to claim there is a distinctive type of teleology which some powers have that means they can be thought to be good when they manifest, whilst other powers have a type of teleology that means they are always axiologically neutral. What type of teleology is this? I have no idea. Maybe axiological teleology? But positing this to restrict the domain of powers involved in goodness seems highly ad hoc. Nevertheless, it is by no means novel to claim that there are distinct, non-reducible, types of teleology (Feser, 2010), and so perhaps there is a type that only some powers have, in virtue of which their manifestations are good? Assume a view like this can be spelt out, still a question might arise as to how we could know which powers were axiologically relevant. Suppose empirically there was no detectable difference, one could still reply to the objection that insofar as it's an epistemological question, one I admit I cannot answer, it doesn't defeat the metaphysical picture. Although there is truth to this, the fact that I cannot answer the epistemological question would be a reason for many to reject this way of restricting the domain of powers that are relevant to goodness. As such, I don't think this option will be taken by many.

Given the failure of these answers to the problem of permissiveness, it seems we need a different way forward. My suggestion will be that we reintroduce objects into our theory. One might worry that this suggestion means I am giving up on a purely powers-based account of goodness. I hope this won't be the case, but before I explain why let me briefly note two further objections to a power trope view with no objects, since it will be helpful to see whether and how a future theory with objects can overcome them.

The first objection, the "bearer worry", concerns the bearer of goodness on a power trope view with no objects. As there are no objects, this view therefore holds that tropes are the bearers of goodness. Whilst this might seem odd, things are made worse on certain views of powers. For instance, on a popular view of powers, what I call the "jumping view", held, for example, by both Bird (2007) and Mumford and Anjum (2011), when a power manifests another different power is produced. ${ }^{46}$ Whilst such views are taken to be prey to a metaphysical objection raised by Armstrong (1997, 80), the always packing never travelling difficulty, my worry concerns what this view implies regarding the bearer of goodness. The problem is that it doesn't seem possible for goodness to be attributed to the power itself on a jumping view. This is because on this view when the power manifests it jumps to being a different power. This means that the power which manifests is no longer in

\footnotetext{
$\overline{45}$ Some who employ this criterion for life don't give it metaphysical import (Thompson, 2008), and given this they might be able to overcome some of these worries.

46 Other views of powers may also hold to this. For instance Oderberg (2007, 130-143) and Feser's (2014a) view of powers claims that a power which isn't manifesting is a potency whilst a power that is manifesting, or has manifested, is an actuality. It seems on their view that potency and actuality are meant to be different things, rather than different states of the numerically same power, and as such they too seem to hold to a jumping type of view.
} 
existence during or after the manifestation since we have a new power instead. As such we can't attribute goodness to the initial power since post manifestation it is no more, and instead we have a different power. This might lead to another related worry, that on the jumping account it seems we will have to say that a power which destroys itself, something all powers do by manifesting, are achieving their good. Is this really something we want to say? I suggest many will want to say no. ${ }^{47}$

Whilst this objection can be overcome by adopting a different view of powers, such as Marmodoro's (2017b, 58-60), on which a power's manifestation is an internal transition from being in a state of potentiality to a state of actuality, resulting in the same power existing before and during its manifestation, we may still not be content in attributing goodness to a trope. ${ }^{48}$ The main reason for this is that attributing goodness to tropes alone doesn't seem to give us many of the types of goodness we prima facie seem to require and that neo-Aristotelians wish to embrace. In stark contrast to the too permissive objection, we can therefore call this the "too restrictive objection". To see the worry, think about types of goodness that we usually attribute to organisms, such as their bodies functioning well in various ways. If we treat organisms as mere heaps of powers then it seems we can't discriminate between good or bad states for an organism and hence determine whether their bodies are functioning well. For instance, on the current account, what would be bad about having a broken arm if it involved the actual manifestation of one's powers? ${ }^{49}$ It seems difficult to say. What is typically thought to make it wrong is made in reference to the whole organism and its holistic functions, in this case being the fact that the organism can no longer function as it ought. It therefore seems that by restricting goodness to tropes we have thereby removed many of the types of goodness we should be giving an account of, namely the goods of composite objects, such as organisms. Given this, we have even more reason to reintroduce objects into our theory, and doing so is what I turn to now.

\section{Powerful objects}

By introducing objects back into our theory one might worry that this means giving up on a purely powers-based account of goodness. I however hope this is not the case. So how can I add objects back into the mix without forfeiting my intended

\footnotetext{
47 Let me note in passing, that this type of problem will affect other entities within a neo-Aristotelian theory of goodness. For instance, take a bomb which is good insofar as it destroys itself at the right place and right time and bad insofar as it doesn't. All neo-Aristotelians about artefactual goodness will need to explain what the bearer of goodness is once the bomb explodes, and insofar as they can they might be able to offer a parallel response to my concern above. Additionally, it's worth noting that in general neoAristotelians about goodness do not think that something needs to be beneficial to the individual in order for it to be good. As long as it falls under the entity's natural norm it is good (Crane \& Sandler, 2011, 304; Lott, 2012; Oderberg, 2020, 96-101).

48 One may also have concerns with Marmodoro's account, for instance asking as to what a 'state' of a power is (McKitrick, 2017, 43) and whether we can understand how a power in these two states is numerically identical.

49 My thanks to a reviewer for this example.
} 
goal of trying to give an account of neo-Aristotelian goodness in terms of powers alone? Marmodoro here is helpful on the two options that are available, writing, 'either assume objects and show them to be powerful; or assume powers and show how objects consist of them.' (2017a, 110) As some standard neo-Aristotelian theories of goodness seem to employ the former, albeit by seemingly removing the need for powers to play any significant role in their theory of goodness, I shall do the latter.

How then are objects supposed to consist of powers? There are multiple proposals that have been formulated as of late, most being forms of hylomorphism, whereby a power plays the role of form uniting other powers which are the object's constituents. ${ }^{50}$ I will outline a few of them in a moment but let me note up front that I will not be, and have no intention of, defending any of these views, at least not here. Rather what I hope to show is how a number of theories that make objects out of powers can respond to the objections raised against the powerful tropes and no objects account of neo-Aristotelian goodness I gave earlier. In this process it should become clear what will be required for a powers view of objects to fit well with a neo-Aristotelian theory of power based goodness, with future work needed to explore which, if any, of the accounts is best for this job. With all that said, let me outline a few accounts. ${ }^{51}$

First is Rea (2011) who takes it that the natures of objects, what he calls substances, are fundamental powers, and further that these natures of composite objects unite other powers, namely their constituents. By way of example he considers humanity to be a biological nature, and so a power, and thinks that the manifestation of humanity in a region depends causally upon a particular sort of cooperative manifestation with the simple parts of the human organism, namely its constituent powers.

Second is Jaworski (2016) who also holds that forms, or what he calls structures, are powers, namely powers to configure (or organise, order, or arrange) an object's material parts into a single whole distinct from other objects. In so doing, Jaworski claims that these single wholes are emergent individuals which are essentially engaged in the activity, which is the manifesting of the 'form' or 'structure' power, of configuring the materials that compose them, that is the powers which are its constituents.

Koons $(2014,2017)$ provides us with a third account and also thinks of causal powers as playing the role of form, whilst additionally allowing that there can be fundamental causal powers at the macro level. These powers exhibit top-down metaphysical grounding on the parts of an object, and in doing so grounds 'the facts about the spatial relationships and causal powers of the chemical and physical components of the organism[/object], enabling those parts to contribute appropriately to the functioning of the whole.' $(2017,4)$.

\footnotetext{
50 Arguably matter, or prime matter, can also be understood as a type of power (Dumsday, 2016b, 622; 2019).

51 Let me also say from the outset that for my purposes I will bypass various subtilties regarding each theory and will also ignore general disagreements and challenges that can be brought against each.
} 
Fourth we have Marmodoro (2017a, b, 2018; Austin \& Marmodoro, 2017), who claims that powers exist in structures. These she takes to be of two types, namely structures that unite, and structures that unify. ${ }^{52}$ Correspondingly, these types of structures are thought to be dependent on two types of powers, namely structural powers, which unite powers when they come together into physical structures, and substantial powers, which unify, such that multiple powers become one. Structural powers therefore bring about some unity between many distinct powers due to their being ontological dependencies between them. Whilst a substantial power brings about a change in the individuation criteria of the multiple powers, and thereby a change in their ontological status. No longer do they exist as a multitude of powers, but rather they are reidentified and unified into one power, with all the power 'parts' depending for their identity on the substantial power. Given this we have two additional ways to think about how powers compose objects. ${ }^{53}$

Fifth, and finally for our purposes, is Dumsday's postulation of multi-track powers (2016b, 615-620). ${ }^{54} \mathrm{He}$ writes, "perhaps the negative charge, half-integral spin, etc., of an electron are all manifestations of one underlying multi-track power to give rise to such properties in the object upon that object's receiving an appropriate external causal stimulus.' (2016b, 616) Whilst Dumsday may allow objects to be more than merely a multi-track power, for our purpose if we wanted a theory of objects based on powers alone, perhaps we could claim that a multi-track power is all that grounds the essential aspects of a composite object. ${ }^{55}$

Whilst there are no doubt other ways to build objects from powers, ${ }^{56}$ this brief overview should provide a flavour as to how some of the most prominent theories have tried to accomplish this task. Now let us consider whether and how these types of accounts can answer previous concerns raised when discussing the powerful tropes and no objects theory of neo-Aristotelian goodness.

We start with the "bearer worry", which claimed that our previous theory of goodness gave the wrong account as to what the bearer of goodness is, namely a power trope rather than an object. The accounts given above largely resolve this worry, in that whilst what makes something good is still the manifestation of powers, these powers, in some way or another, make an object. As such we get the right result on most of the views, with the bearer of goodness being, for example, a human being, rather than a power trope, even though a human being ends up being nothing more than some type of power uniting, configuring, grounding, or unifying

\footnotetext{
52 I take it that Marmodoro thinks of this uniting relationship differently to Rea.

53 Note that Marmodoro wouldn't follow this exactly, since she says, 'Although every structure of powers could be thought of as a structural power, I reserve the term "structural power" for those structures of powers which constitute substantial powers.' (2017a, 122) I will use structural power more liberally than she does, so to differentiate the two accounts.

54 Johnston (2006, 663-664) seems to have floated an idea that is in some ways like this. Note also that Dumsday (2016b, 620-624) talks about a single-track view as well, but due to space here I ignore it.

55 I ultimately would still be happy with a theory of objects that required more than powers, so long as powers played the key role in our theory of goodness. However, here I try to give accounts based on powers alone in order to ensure they are central.

56 For example, perhaps a powers inspired view of Keinänen and Tahko's (2019) work and a power interpretation of Paul's (2017) ontology would also do the job.
} 
its constituent powers. ${ }^{57}$ The only view on which trouble seems to remain concerns Dumsday's multi-track view, since it still seems that the bearer of goodness is a trope. Nevertheless, one may wish to call this individual multi-track trope an object and given things I have said elsewhere I am in principle open to this suggestion (Page, 2017, 94), however I suspect some will be resistant and this will be a cost of the view.

Turn to another previous concern, what I called the "too restrictive objection". Through our introduction of objects we can now have goods relating to the whole organism rather than just to individual tropes. The reason for this, at least for the first four accounts, is due to the fact that there is a power, what I will call the "primary power", that in some way unites, configures, grounds, or unifies its constituent powers into an individual and as such provides these constituent powers, in some way, with a new holistic function. ${ }^{58}$ As such the goods of the object will be to do with how well this primary power achieves this end, namely of continually bringing about this result, and how well the constituent powers achieve their new holistic function, which often will be directed towards, in one way or another, making sure the primary power can continue to reach it's end. This also allows the theory to say that there is derivative goodness as well, since now there will be parts of the object, certain of its powers, which may help the primary power manifest in various ways. ${ }^{59} \mathrm{We}$ can also now provide an explanation of why a broken arm is bad for a human, and claim that it is because the arm can no longer fulfil its role as it ought to, a function conferred on the powers which constitute the arm by the primary power which unites, configures, grounds, or unifies a human being.

On the multi-track view, a slightly different answer needs to be given. Here we can say, for example, that the essentials of an organism are grounded by a multitrack power, and as such the goods of the organism depend on which tracks are manifesting and whether they are manifesting in the correct circumstances. Additionally, given what organisms can do, it seems that this would need to be a type of multi-track power that can manifest more than one of its tracks simultaneously. As such an organism would be good insofar as it is manifesting the tracks it ought to in the situation it is in. We could additionally add that some of the tracks of this power may require the manifestation of other tracks in order to achieve their end, with this type of condition being something I have made use of elsewhere (Page, 2017, 98-99). This will allow us to make sense of the broken arm example as well, since the multi-tracker can claim that the arm being broken is bad

\footnotetext{
57 Further note that given the role that the primary power plays, it would seem implausible that it be a "jumping" type of power, since this power is typically thought to explain the persistence of an object, such as living things, through the dynamic changes they may undergo throughout their life.

58 Where the details of how this is done may vary amongst the accounts.

59 How exactly this works will likely vary from proposal to proposal and deserves more attention in the future. One option may be to claim that after the primary power has performed its initial task of uniting/configuring/grounding/and unifying the constituent powers and providing them with their holistic function, these constituent powers need to manifest their holistic function to such an extent to maintain the manifesting of the primary power. Why and how this works, or whether one should say something else, will have to wait another time.
} 
insofar as it prevents other tracks of the multi-track power to manifest since they require the arm to do a job it is currently unable to do in its broken state.

Finally, we come to the "problem of permissiveness". One way we can now restrict which powers play a role in goodness is by saying that only the power that unites/configures/grounds/and unifies an object and the constituent powers of the object may be good. This will therefore rule out many powers, those not making up objects, as being good or bad. ${ }^{60}$ Once again things will be a little different for a pure multi-track view, given that we will need a criterion so to classify certain multitrack powers as grounding an object's essence, something I will turn to shortly. Nevertheless, I should note that it might be the case that even a restriction to objects will not be enough to do the job. The reason for this is that some of things the theories classify as objects we may wish to say are not things that can be good. For instance, take Marmodoro's structural powers view, which unites powers but does not unify them. This seems to still provide an account that is too permissive, given that it allows that very many types of things compose a structural power, such as 'the grains of sand on the beach.' (2017a, 118) However, if grains of sand on a beach can satisfy the condition for a structural power then we will be left with a very permissive account of objects, and as such the problem of permissiveness will continue to rear its head.

However, if we adopt Marmodoro's view where a power brings about unification of other powers we will be able to rule out more objects, since unification is a far stricter condition of objecthood than her uniting. Rea's, Jaworski's and Koon's views will also be able to rule out the permissive objects mentioned above, and therefore they too will do a fairly good job in restricting what is good. Nevertheless, whilst restricting goodness to objects may help with the problem of permissiveness, we might still think there is too much permissiveness. To see this note that on some of the views, ${ }^{61}$ objects will come in two varieties, the living and the non-living, and yet we may plausibly wish to rule out non-living types of objects from being good.

Thus, supposing we want to limit what can be good to living organisms, we could formulate a theory of composition which only allows organisms to satisfy it, and claim that this is a condition for something being good. ${ }^{62}$ Arguably, this is something Koons's (2014) view is meant to achieve, and in its full form is supposed to apply just to the living. There may be other ways of doing this, perhaps by saying only those things caught up in a life (van Inwagen, 1990, 94-95), whatever this ends up meaning, or those things which can bring about self-perfection, as my life-type

\footnotetext{
60 A good question is why restrict goodness to objects, after all some might not be concerned about doing this (Oderberg, 2020) and therefore the problem of permissiveness more generally. Here I point only to the fact that it conforms with one's intuitions more than the former view does. However, this requires further justification in the future.

61 For instance Marmodoro's, which allows non-living things to be unified into objects, such as an electron (2017a, 122), whilst Jaworski holds it as an empirical possibility that there be non-living objects informed by his structure, which it will be remembered, is a type of power $(2016,150)$.

62 Perhaps as per a reviewer's suggestion, 'living things have a kind of substantial unity that non-living things lack, and it is that unity that is crucial' in making sense of things being good or bad.
} 
teleology above had it, can be good, but investigating this further and determining whether it is ad hoc will require future work. ${ }^{63}$

Turning to the multi-track view, we could also restrict goodness to objects, however we would need to come up with a criterion that implied some multi-track powers counted as objects whilst others didn't. One suggestion would be to claim that only those multi-track powers which have tracks that are dependent on the manifestation of its other tracks count as objects. Yet whilst one concern here would be the potential ad hoc-ness of this type of account, it also seems as though we could be left with too many multi-track powers that can be good, and hence permissiveness will still be a concern. Another option would be to make a parallel move to the one made above and claim that only those multi-track powers involved in self-perfection, or life, can be said to be good, and as such the only multi-track powers relevant here are those concerning living objects. Once again, however, further work is required here, since more will need to be said about whether a multitrack power can fulfil the conditions for self-perfection and how it will do so. Unfortunately this too will have to wait for another time.

With all this said, hopefully one can see how a powers view of objects has the means to solve the difficulties raised against the view of goodness with no objects, even if the proposed responses need more attention in the future. It would be nice to conclude which, if any, of the power based theory of objects is best suited for the job, but unfortunately that would require far more words than I have at my disposal here. Nevertheless, I hope it is clear how one could develop a powers based theory of goodness on each of these accounts. But, it would be unfair to make out that things are wholly plain sailing for these views as there is at least one difficult question for the views which deserves a comment, although unfortunately I can once again do no more than raise it here and sketch some possible avenues for future exploration.

Consider what I call "the infected leg scenario", whereby my leg becomes so infected, that unless I remove it the infection will spread to the rest of my body and cause me permanent serious illness and eventual death. I suggest that most would think that the function of the leg, say to move, should be sacrificed so that the rest of my body can function properly. That is both functions are not of equal value, and one should be thought more valuable than the other. By way of illustration, on the primary power account of objects, we can say that the manifestation and continual manifesting of this power is the primary end of a human, since it makes a human being a human, and as such it is the end that is most important. Given this, the reason why I should remove my leg is because by not doing so I would ultimately stop the primary power from doing its job. By contrast, the removal of my leg will do no such thing and as such is of less value. ${ }^{64}$

\footnotetext{
63 Basl and Sandler $(2013,702)$ don't seem to think that making us of 'life' here will help and I suspect this is because they assume an etiological account of teleology. However, I think this analysis of teleology is false for several reasons (for references see footnote 23).

64 At most it may be that my leg, which is a constituent power, helps to maintain the manifesting of the primary power when it manifests its holistic function. However as the primary power isn't fully dependent upon this, it is still able to continue manifesting and reaching its end. As I noted in footnote 59,
} 
Complexities aside, so far so good. However there is a difficulty, namely how are we to understand the nature of this primary power? Should we think of it as singletrack or multi-track? If it's single-track then assuming we can determine what its end is, we will know what the primary end and therefore primary good is for the organism. By contrast if its multi-track things are more complicated. ${ }^{65}$ This is because we will need to work out which, if any of the tracks, should be prioritised if they ever come into conflict. The answer here should be that the most fundamental track, the one most required in order for the organism to continue to exist, should be given priority, yet determining what this track is will likely be a tricky business. ${ }^{66}$ One should also note that the single-track may also be subject to fundamentality concerns, albeit in a different way, since they too will have to work out an order of fundamentality of the single-track powers of the organism, since they will need to know which power to prioritise if their ends conflict. I suspect the best response to these latter concerns is to adopt what hylomorphists have generally claimed when facing similar issues, namely that we ought to rely on empirical investigation (Jaworski, 2016), or empirically informed metaphysical theorising (Oderberg, 2007, 13), to determine which end or ends are most fundamental. ${ }^{67}$ However, as I said above, this whole question deserves additional research in the future.

\section{Conclusion}

The general blueprint is now complete, and hopefully it is now fairly clear, albeit in broad brush strokes, what a powers based account of neo-Aristotelian natural goodness might look like. As I've noted throughout the paper, there are many additional complexities to be investigated further, specific areas of the blueprint to be focused on, but doing so will have to wait until another occasion. Whilst it may be disappointing that I've been unable to spell out a powers theory of natural goodness in fine detail here, it shouldn't be surprising, after all this is a very large project indeed. Additional complexities will also be raised if one tries to extend the account to incorporate both moral and artefactual goodness, but these too will have to wait another time. Nevertheless, hopefully what I've said in this paper is enough

Footnote 64 continued

this will require further spelling out in the future, and I suspect how this is done will somewhat depend on the theory of objects adopted.

65 This complication will also hold for Dumsday's multi-track view of objects given above. Note also that none of the primary power view of objects given above speak of multi-track powers (although they don't explicitly speak of single-track powers either). However as their primary power often appears to have more than one role or end, we might be inclined to think of this power as being multi-track. For instance Jaworski's structure, his primary power, does multiple things, and Rea seems to imply the same when speaking of a 'complex' power (2011, 348 \& 356, n.12).

66 There may be additional questions here to be raised such as what type of fundamentality is important, e.g. ontological or causal or something else.

67 Note that questions of fundamental ends or natures can also be raised against more typical neoAristotelian accounts of goodness, and so unless there are particular difficulties due to the nature of powers, the theory I give here is no worse off. 
to provide an answer to the question I started with, namely, whether one can give an account of neo-Aristotelian natural goodness in terms of powers? Given what I've said in this paper, my answer is yes, I think so.

Open Access This article is licensed under a Creative Commons Attribution 4.0 International License, which permits use, sharing, adaptation, distribution and reproduction in any medium or format, as long as you give appropriate credit to the original author(s) and the source, provide a link to the Creative Commons licence, and indicate if changes were made. The images or other third party material in this article are included in the article's Creative Commons licence, unless indicated otherwise in a credit line to the material. If material is not included in the article's Creative Commons licence and your intended use is not permitted by statutory regulation or exceeds the permitted use, you will need to obtain permission directly from the copyright holder. To view a copy of this licence, visit http:// creativecommons.org/licenses/by/4.0/.

\section{References}

Ariew, A. (2002). 'Platonic and Aristotelian roots of teleological arguments. In A. Ariew, R. Cummins, \& M. Perlman (Eds.), Functions. Oxford University Press.

Armstrong, D. M. (1997). A world of states of affairs. Cambridge University Press.

Austin, C. J. (2019). Essence in the age of evolution. Routledge.

Austin, C. J., \& Marmodoro, A. (2017). Structural powers and the homeodynamic unity of organisms. In W. M. R. Simpson, R. C. Koons, \& N. J. Teh (Eds.), Neo-Aristotelian perspectives on contemporary science. Routledge.

Basl, J., \& Sandler, R. (2013). The good of non-sentient entities. Studies in History and Philosophy of Biological and Biomedical Sciences, 44, 697-705.

Bauer, M. (2009). Normativity without artifice. Philosophical Studies, 144, 239-259.

Bauer, W. A. (2016). Physical intentionality, extrinsicness, and the direction of causation. ActaAnalytica, 31, 397-417.

Beere, J. (2009). Doing and being. Oxford University Press.

Bird, A. (2007). Nature's metaphysics: Laws and properties. Oxford University Press.

Bohn, E. D. (2018). Normativity all the way down: From normative realism to pannormism. Synthese, 195, 4107-4124.

Borghini, A. (2009). Dispositions and their intentions. In G. Damschen, R. Schnepf, \& K. R. Stüber (Eds.), Debating dispositions: Issues in metaphysics, epistemology and philosophy of mind. Walter de Gruyter.

Crane, J. K., \& Sandler, R. (2011). Species concepts and natural goodness. In J. K. Campbell, M. O'Rourke, \& M. H. Slater (Eds.), Carving nature at its joints. MIT Press.

Cronin, M. (1930). The science of ethics (Vol. 1). M. H. Gill and Son.

Des Chene, D. (2000). Life's forms. Cornell University Press.

Dumsday, T. (2016a). Lowe's unorthodox dispositionalism. Res Philosophica, 93, 79-101.

Dumsday, T. (2016b). Natural-kind essentialism, substance ontology, and the unity problem. Dialectica, 70, 609-626.

Dumsday, T. (2019). Can a relational substance ontology be hylomorphic?, Synthese 1-18.

Feser, E. (2014a). Scholastic metaphysics: A contemporary introduction. EditionesScholasticae.

Feser, E. (2014b). Being, the good, and the guise of the good. In D. Novotny \& L. Novak (Eds.), NeoAristotelian perspectives in metaphysics. Routledge.

Feser, E. (2019). Aristotle's revenge. EditionesScholasticae.

Fine, K. (1994). Essence and modality. Philosophical Perspectives, 8, 1-16.

Foot, P. (2001). Natural goodness. Oxford University Press.

Frey, J. A. (2019). Neo-Aristotelian ethical naturalism. In T. Angier (Ed.), The cambridge companion to natural law ethics. Cambridge University Press.

Geach, P. T. (1956). Good and evil. Analysis, 17, 33-42.

Hacker-Wright, J. (2013). Phillipa foot's moral thought. Bloomsbury.

Haldane, J. (1999). Insight, inference and intellection. Proceedings of the American Catholic Philosophical Association, 73, 31-45. 
Heil, J. (2003). From an ontological point of view. Oxford University Press.

Hursthouse, R. (2013). Neo-Aristotelian ethical naturalism. In H. LaFollette (Ed.), The international encyclopedia of ethics. Blackwell.

Jaworski, W. (2016). Structure and the metaphysics of mind. Oxford University Press.

Johnston, M. (2006). Hylomorphism. The Journal of Philosophy, 103, 652-698.

Keinänen, M., \& Tahko, T. E. (2019). Bundle theory with kinds. The Philosophical Quarterly, 69, $838-857$.

Kenny, A. (1988). Cosmological explanation and understanding. In L. Hertzberg \& J. Pietarinen (Eds.), Perspectives on human conduct. E. J. Brill.

Koons, R. C. (1998). Teleology as higher-order causation: A situation-theoretic account. Minds and Machines, 8, 559-585.

Koons, R. C. (2000). Realism regained. Oxford University Press.

Koons, R. C. (2014). Staunch versus faint-hearted hylomorphism. Res Philosophica, 91, 151-177.

Koons, R. C. (2017). The ontological and epistemological superiority of hylomorphism, Synthese 1-19.

Koons, R. C., \& Pruss, A. (2017). Must functionalists be Aristotelians. In J. D. Jacobs (Ed.), Causal powers. Oxford University Press.

Kroll, N. (2017). Teleological dispositions. Oxford Studies in Metaphysics, 10(3), 37.

Lisska, A. (1996). Aquinas's theory of natural law: An analytic reconstruction. Oxford University Press.

Lisska, A. J. (2016). Aquinas's theory of perception. Oxford University Press.

Lott, M. (2012). Have elephant seals refuted Aristotle? Journal of Moral Philosophy, 9, 353-375.

Loux, M. J. (2014). Aristotle's hylomorphism. In D. D. Novotný \& L. Novák (Eds.), New-Aristotelian perspectives in metaphysics. New York: Routledge.

Lowe, E. J. (1989). Kinds of being. Blackwell.

Lowe, E. J. (2009). More kinds of being. Wiley Blackwell.

Lowe, E. J. (2010). On the individuation of powers. In A. Marmodoro (Ed.), The metaphysics of powers. Routledge.

Lowe, E. J. (2018). Metaphysics as the science of essence. In A. Carruth, S. Gibb, \& J. Heil (Eds.), Ontology, modality, and mind: Themes from the metaphysics of E. J. Lowe. Oxford University Press.

Makin, S. (2006). Aristotle: Metaphysics book $\Theta$. Clarendon Press.

Manley, D., \& Wasserman, R. (2017). Dispositions without teleology. Oxford Studies in Metaphysics, 10, 47-59.

Marmodoro, A. (2017a). Power mereology: Structural versus substantial powers. In M. P. Paoletti \& F. Orilia (Eds.), Philosophical and scientific perspectives on downward causation. Routledge.

Marmodoro, A. (2017b). Aristotelian powers at work: Reciprocity without symmetry in causation. In J. D. Jacobs (Ed.), Causal powers. Oxford University Press.

Marmodoro, A. (2018). Potentiality in Aristotle's Metaphysics. In K. Engelhard \& M. Quante (Eds.), Handbook of Potentiality. Dordrecht: Springer.

Marmodoro, A. (unpublished). What's dynamic about causal powers? A black box!

Martin, C. B. (2007). The mind in nature. Oxford University Press.

McKitrick, J. (2017). Indirect directness. Oxford Studies in Metaphysics, 10, 38-46.

McKitrick, J. (2018). Dispositional pluralism. Oxford University Press.

Molnar, G. (2003). Powers: A study in metaphysics. Oxford University Press.

Mumford, S. (1998). Dispositions. Oxford University Press.

Mumford, S., \& Anjum, R. L. (2011). Getting causes from powers. Oxford University Press.

Oderberg, D. S. (2000). Moral theory. Blackwell.

Oderberg, D. S. (2007). Real essentialism. Routledge.

Oderberg, D. S. (2010). Metaphysical foundations of natural law. In H. Zaborowski (Ed.), Natural moral law in contemporary society. Catholic University of America Press.

Oderberg, D. S. (2017). Finality revived: Powers and intentionality. Synthese, 194, 2387-2425.

Oderberg, D. S. (2020). The metaphysics of good and evil. Routledge.

Okrent, M. (2007). Rational animals: The teleological roots of intentionality. Ohio University Press.

Okrent, M. (2018). Nature and normativity. Routledge.

Page, B. (2017). The 'Power'-ful trinity. European Journal for Philosophy of Religion, 9, 87-112.

Page, B. (forthcoming). The metaphysics of powers, Internet Encyclopedia of Philosophy.

Paul, L. A. (2017). A one category ontology. In J. A. Keller (Ed.), Being, freedom, and method. Oxford University Press.

Place, U. T. (1999). Intentionality and the physical: A reply to Mumford. The Philosophical Quarterly, 49, 225-231. 
Plantinga, A. (1993). Warrant and proper function. Oxford University Press.

Rea, M. C. (2002). World without design. Oxford University Press.

Rea, M. C. (2011). Hylomorphism reconditioned. Philosophical Perspectives, 25, 341-358.

Rosenkrantz, G. S. (2012). Animate beings: Their nature and identity. Ratio, 25, 442-462.

Schmid, S. (2011). Teleology and the dispositional theory of causation in Thomas Aquinas. Logical Analysis and the History of Philosophy, 14, 21-39.

Shields, C. (2012). The dialectic of life. Synthese, 185, 103-124.

Silverstein, M. (2016). Teleology and normativity. Oxford Studies in Metaethics, 11, 214-240.

Teichmann, R. (2011). Nature, reason and the good life. Oxford University Press.

Thompson, M. (1995). The representation of life. In R. Husrthouse, G. Lawrence, \& W. Quinn (Eds.), Virtues and reasons. Clarendon Press.

Thompson, M. (2008). Life and action. Harvard University Press.

van Inwagen, P. (1990). Material beings. Cornell University Press.

Vetter, B. (2015). Potentiality: From dispositions to modality. Oxford University Press.

Whittle, A. (2008). A functionalist theory of properties. Philosophy and Phenomenological Research, 77, 59-82.

Williams, N. E. (2011). Putting powers back on multi-track. Philosophia, 39, 581-595.

Witt, C. (2008). Aristotelian powers. In R. Goff (Ed.), Revitalizing causality. Routledge.

Publisher's Note Springer Nature remains neutral with regard to jurisdictional claims in published maps and institutional affiliations. 